(c) American Dairy Science Association, 2002.

\title{
Effect of Heat Stress On Nonreturn Rate in Holstein Cows: Genetic Analyses
}

\author{
O. Ravagnolo ${ }^{1}$ and I. Misztal \\ Department of Animal and Dairy Science, \\ University of Georgia, Athens 30602
}

\begin{abstract}
The genetic component in heat tolerance for nonreturn rate in Holsteins was estimated using an animal linear model augmented by a random regression on a temperature-humidity index (THI). Data consisted of 18,059 nonreturn rates at 45,60 , and $90 \mathrm{~d}$ after insemination and 81,674 first-parity test-day milk yields from 78 herds in Florida. The THI on the day of insemination or test day was added to each record. Only first-insemination records were used. The model for nonreturn rate included the effects of herd-year-season, age, days in milk, milk yield, THI as a covariable, regular additive effect, and random regression on THI for heat-tolerance additive effect. With a single-trait model, heritability estimates for NR45, NR60, and NR90 at THI $=70$ for first-lactation cows were $0.006,0.014$, and 0.053 , respectively. Genetic correlation between regular NR90 and heat tolerance was -0.95 . A bivariate analysis for NR90 and test-day milk production yielded a correlation between regular merit and heat tolerance for NR90 of -0.35 , substantially lower than by the univariate model, indicating a bias in the univariate estimates caused by ignored selection. The regular genetic correlation between NR90 and milk yield was -0.41 . Genetic correlation between heat tolerance for NR90 and heat tolerance for milk yield was -0.04 , indicating the need to separate selection.
\end{abstract}

(Key words: heat stress, dairy cattle, nonreturn rate, temperature-humidity index)

Abbreviation key: $\mathbf{N R}=$ nonreturn rate, $\mathbf{T H I}=$ temperature-humidity index.

\section{INTRODUCTION}

Animals experience stress when their environment has a noticeable and negative change. This change can

\footnotetext{
Received August 13, 2001.

Accepted October 16, 2002.

Corresponding author: I. Misztal; e-mail: ignacy@uga.edu.

${ }^{1}$ Current address: Instituto Nacional de Investigación Agropecuaria, Las Brujas, Uruguay.
}

be temporary-in which case, the reaction to the change by the animal will end as soon as the disrupting effect ends - or be permanent-in which case the animal will try to adapt to the new situation. In case of heat stress, animals will reduce both production and reproduction in order to adapt to the new situation (Bianca, 1965). Heat stress is any combination of environmental parameters producing conditions that are higher than the temperature range of the animal's thermal neutral zone (Buffington et al., 1981). Important economic losses in production and reproduction have been extensively documented. Improving heat tolerance genetically has been the topic of several studies. Efforts to obtain highly productive dairy cattle in hot climates through crossbreeding have been, until now, unsuccessful (McDowell et al., 1996). Hansen et al. (2000) mentions that certain tropically adapted breeds are more resistant to high temperatures at the cellular level. Identification of the genes responsible for enhanced cellular resistance to heat shock may allow genes to be transferred into thermally sensitive breeds in the future and thus improve heat tolerance in high-yielding breeds. Olson et al. (1997) investigated the existence of a major gene influencing heat tolerance in Senepol cattle. They found that rectal temperatures of "slick" calves were lower than their normal-coated counterparts and that they were heavier at birth but had no differences in respiration rate. They concluded that a major gene for hair length and heat tolerance might exist in the Senepol breed because of the lower rectal temperatures found in animals with the "slick" coat. An alternative to improving performance in hot climates is to select for heat tolerance within the breeds. Several authors have found important differences between animals when studying the effect of heat stress on respiration rate, body temperature, and milk yield, with most heritability estimates ranging from 0.10 to 0.50 (Branton et al., 1953; Gomes da Silva, 1973; Seath, 1947). Ravagnolo and Misztal (2000) concluded that genetic variation for heat tolerance was as important as the regular additive variance (the genetic ability to produce milk independently of heat stress) when animals were exposed to heat stress and that selection for milk production and heat tolerance is possible because of the low negative correla- 
tion between them. Nardone and Valentini (2000) simulated selection schemes for heat tolerance in high-yielding breeds and for milk yield in highly adapted local breeds to see which scheme would yield better results. They concluded that selection based on rectal temperature of a high-yielding breed was the most efficient because heat tolerance can be improved in a few generations for the high-yielding breed, whereas a local breed would need several generations (more than 30 ) to reach comparable milk production levels.

Ravagnolo et al. (2000) proposed a model to quantify heat stress through a temperature humidity index (THI) on the day of the insemination. They found that nonreturn rate started to decline between THI 66 and 70 depending on the state analyzed and that loss of nonreturn rate after that threshold was around 0.005 and 0.007 per unit increase in THI.

Following our previous studies in heat tolerance, the objectives of this paper are to

1) develop a genetic model that explains the genetics of heat tolerance for nonreturn rate (NR);

2) quantify additive components for heat tolerance for $\mathrm{NR}$; and

3) analyze genetic relationships between regular merit and heat tolerance for NR and milk yield in first lactation.

\section{MATERIALS AND METHODS}

\section{Analysis of NR45, NR60 and NR90 for First Lactation}

Data comprised insemination records from 18,059 first-lactation Holstein cows from 78 herds in Florida, collected from 1995 to 1999 . Nonreturn rate at 45, 60, and 90 (NR45, NR60, NR90) days after first insemination was calculated only for first inseminations with a value of 1 assigned to cows that did not return to insemination (i.e., assumed pregnant) and 0 for cows that were inseminated a second time within 45,60 , or $90 \mathrm{~d}$. Cows were assumed pregnant if a subsequent insemination was not reported within 45,60 , or $90 \mathrm{~d}$ after the initial service. Nonreturn rate at later inseminations was ignored because of the data's likely incompleteness and the lack of independence between successive inseminations for second and later inseminations. Breeders may choose more fertile sires, and eventually sires for natural service may be used (Thaller, 1997). NR60 and NR90 were included with the expectation that they would provide more reliable information concerning true pregnancies and thus obtain higher heritability estimates.

Weather data consisted of daily maximum temperature in ${ }^{\circ} \mathrm{C}(\mathrm{t})$ and daily minimum humidity (h) from several weather stations throughout Florida. The weather data assigned were from the day of the insemination according to results from our previous study (Ravagnolo and Misztal, 2002). Augmentation of the reproductive data with the weather data was as described in Ravagnolo and Misztal (2002). THI was calculated with these two variables for each NR using the following formula:

$$
\begin{gathered}
\text { THI }(\mathrm{t}, \mathrm{h})=9 / 5 \mathrm{t}+32 \\
-11 / 2(1-\mathrm{h})(9 / 5 \mathrm{t}-26)(\text { NOAA, 1976). }
\end{gathered}
$$

\section{Statistical Analyses}

Five age classes were defined by every 3-mo interval starting at 24 mo of age. Days in milk classes were defined as one class for every $30 \mathrm{~d}$ (the first class starting at DIM 30) resulting in five classes in which the last class included data from 150 to 200 DIM. Milk production classes were defined by total production in the first $3 \mathrm{mo}$ and divided into four classes containing similar amount of information. Data with THI $<50$ and $>84$ were edited and effective THI (eTHI) was constructed. Results from our previous study (Ravagnolo and Misztal, 2002) indicated that NR for Florida starts to decline at THI 70. Therefore, the following formula was used:

eTHI $=$ THI-70 for THI $>70$ and $\mathrm{eTHI}=0$ otherwise.

Distribution of eTHI classes is shown in Table 1.

The univariate model was defined as:

$$
\begin{aligned}
\mathrm{y}_{\mathrm{ijklmno}}=\text { hys }_{\mathrm{i}}+ & \operatorname{age}_{\mathrm{j}}+\operatorname{dim}_{\mathrm{k}}+\operatorname{milk}_{\mathrm{l}}+\mathrm{f}(\mathrm{m}) \mathrm{b}_{0}+\mathrm{a}_{\mathrm{n}} \\
& +\mathrm{f}(\mathrm{m}) \mathrm{v}_{\mathrm{n}}+\mathrm{e}_{\mathrm{ijklmno}}
\end{aligned}
$$

where $y_{i j k l m n o}$ is NR45, NR60, NR90 (0 and 1) in herdyear-season i, age class j, DIM class $k$, milk-production class 1 , and level $\mathrm{m}$ of the heat stress function; hys $\mathrm{s}_{\mathrm{i}}$ is fixed effect of herd-year-season combination $i(i=1, \ldots$, 776), with seasons defined in four classes every 3-mo period; age $e_{j}$ is effect of age $\mathrm{j}(\mathrm{j}=1,5)$; $\operatorname{dim}_{k}$ is effect of DIM class $\mathrm{k}(\mathrm{k}=1,5)$; milk $\mathrm{k}_{\mathrm{l}}$ is effect of milk-production class $l(1=1-4) ; b_{0}$ is a covariate for the heat stress function $\mathrm{f}(\mathrm{m})$, which is eTHI at the day of insemination; $a_{n}$ is the effect of the additive regular merit of cow $n$ $(\mathrm{n}=1-30117) ; \mathrm{f}(\mathrm{m})$ is the heat stress function; $\mathrm{v}_{\mathrm{n}}$ is the additive linear effect of heat tolerance of cow $n$; and $\mathrm{e}_{\mathrm{ijklmno}}$ is the residual.

In this model, the effect of the inseminated cow is considered as an additive genetic effect. In preliminary analysis, service sire (mate) was included as a random environmental effect, but because the corresponding variance component was very low, this effect was dropped in order to simplify computations. 
Table 1. Distribution, mean, and standard deviation of NR45, NR60, and NR90 for effective temperaturehumidity index (eTHI) classes.

\begin{tabular}{|c|c|c|c|c|c|c|c|}
\hline \multirow[b]{2}{*}{ eTHI } & \multirow[b]{2}{*}{ Obs. } & \multicolumn{2}{|c|}{ NR45 } & \multicolumn{2}{|c|}{ NR60 } & \multicolumn{2}{|c|}{ NR90 } \\
\hline & & Mean & Std. dev. & Mean & Std. dev. & Mean & Std. dev. \\
\hline 0 & 6759 & 0.611 & 0.487 & 0.548 & 0.498 & 0.494 & 0.500 \\
\hline 1 & 849 & 0.585 & 0.493 & 0.524 & 0.500 & 0.479 & 0.499 \\
\hline 2 & 741 & 0.573 & 0.495 & 0.490 & 0.500 & 0.443 & 0.497 \\
\hline 3 & 982 & 0.614 & 0.487 & 0.553 & 0.497 & 0.487 & 0.500 \\
\hline 4 & 777 & 0.585 & 0.493 & 0.497 & 0.500 & 0.425 & 0.495 \\
\hline 5 & 854 & 0.557 & 0.497 & 0.489 & 0.500 & 0.431 & 0.495 \\
\hline 6 & 704 & 0.551 & 0.498 & 0.473 & 0.500 & 0.399 & 0.490 \\
\hline 7 & 892 & 0.565 & 0.496 & 0.477 & 0.500 & 0.383 & 0.486 \\
\hline 8 & 863 & 0.563 & 0.496 & 0.484 & 0.488 & 0.392 & 0.488 \\
\hline 9 & 607 & 0.529 & 0.500 & 0.430 & 0.495 & 0.333 & 0.472 \\
\hline 10 & 1027 & 0.503 & 0.500 & 0.404 & 0.491 & 0.318 & 0.466 \\
\hline 11 & 958 & 0.491 & 0.500 & 0.403 & 0.491 & 0.326 & 0.469 \\
\hline 12 & 944 & 0.452 & 0.498 & 0.343 & 0.475 & 0.249 & 0.433 \\
\hline 13 & 747 & 0.454 & 0.498 & 0.360 & 0.480 & 0.2677 & 0.443 \\
\hline 14 & 355 & 0.493 & 0.500 & 0.391 & 0.489 & 0.293 & 0.455 \\
\hline Total obs. & & & 18,059 & & 18,059 & & 18,059 \\
\hline Mean & & & 0.566 & & 0.489 & & 0.420 \\
\hline SD & & & 0.496 & & 0.499 & & 0.494 \\
\hline
\end{tabular}

The variance covariance structure for the additive components in the univariate model is

$$
\operatorname{Var}\left[\begin{array}{l}
a \\
v \\
e
\end{array}\right]=\left[\begin{array}{ccc}
A \sigma_{a}^{2} & A \sigma_{a v} & 0 \\
A \sigma_{a v} & A \sigma_{v}^{2} & 0 \\
0 & 0 & I \sigma_{e}^{2}
\end{array}\right] .
$$

The heat tolerance effect determines the relative change in NR for each unit increase in the heat stress function. In this model, the random regression is on the eTHI; and thus, each animal will have a different expected breeding value (EBV) at each level of eTHI.

Heritabilities for the univariate model for the different levels of eTHI were computed as follows:

$$
h_{f(m)}^{2}=\frac{\sigma_{a}^{2}+f(m)^{2} \sigma_{v}^{2}+2 f(m) \sigma_{a v}}{\sigma_{a}^{2}+f(m)^{2} \sigma_{v}^{2}+2 f(m) \sigma_{a v}+\sigma_{e}^{2}} .
$$

Genetic correlation between regular merit and heat tolerance for the univariate model was computed as

$$
\operatorname{corr}[a, f(m) v]=\frac{f(m) \sigma_{a v}}{\sqrt{\sigma_{a}^{2} * f(m)^{2} \sigma_{v}^{2}}} .
$$

\section{Analysis for NR90 and Milk Yield for First Lactation}

To analyze the relationship between reproduction and production, the dataset was augmented with testday milk yield from first lactation. After editing, 10,162 cows with NR90 information had at least 1 test-day milk yield record. Editing consisted of removing records with DIM $<5$ and age at calving $<20$ mo, and milk yield $<20$ and $>120 \mathrm{lb}$ with THI $>49$ and $<84$. The first age class consisted of ages between 20 and $22 \mathrm{mo}$, and later classes were defined every 3 mo, resulting in a total of six age classes. Basic statistics of the data for NR and milk are included in Table 2. Evidence suggests that producers try to avoid breeding during hot seasons because average eTHI is higher for milk yield observations than for NR90 observations.

A univariate model was used for NR90 with NR90 multiplied by 10 for computational reasons. The following model was used for milk yield:

$$
\begin{gathered}
\mathrm{y}_{\mathrm{ijklmn}=\mathrm{HTD}_{\mathrm{i}}}+\text { age }_{\mathrm{j}}+\operatorname{dim}_{\mathrm{k}}+\text { freq }_{\mathrm{l}}+\mathrm{m}_{\mathrm{m}}+\mathrm{f}(\mathrm{i}) * \mathrm{~h}_{\mathrm{m}} \\
+\mathrm{p}_{\mathrm{m}}+\mathrm{f}(\mathrm{i})^{*} \mathrm{q}_{\mathrm{m}}+\mathrm{e}_{\mathrm{ijklmn},}
\end{gathered}
$$

where $y_{i j k l m n}$ is test-day yield in herd-test-day $i$, age class $\mathrm{j}$, with milking frequency class 1 , DIM class $\mathrm{k}$, of

Table 2. Basic statistics for the dataset.

\begin{tabular}{lcc}
\hline & \multicolumn{1}{c}{ Test-day } \\
milk & NR90 $^{1}$ \\
\hline Observations & 81,674 & 18,059 \\
Cows & 10,162 & 18,059 \\
Herds & 70 & 78 \\
Mean & 28.40 & 0.42 \\
SD & 6.93 & 0.49 \\
Mean eTHI & & 4.55 \\
SD eTHI & 5.88 & 4.68 \\
Test days/cow (mean) & 5.03 & $\ldots$ \\
Test days/cow (SD) & 8.04 & $\ldots$ \\
\hline
\end{tabular}

${ }^{1} \mathrm{NR}=$ Nonreturn rate at $90 \mathrm{~d}$ after insemination.

${ }^{2} \mathrm{eTHI}=$ Effective temperature-humidity index. 
animal $\mathrm{m} ; \mathrm{HTD}_{\mathrm{i}}$ is effect of herd test-day $\mathrm{i}(\mathrm{i}=1$ to 2186); age $_{j}$ is effect of age class $j(j=1$ to 6$) ; \operatorname{dim}_{k}$ is effect

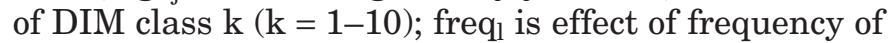
milking $\mathrm{l}(1=1,2) ; \mathrm{m}_{\mathrm{m}}$ is the effect of the additive regular merit of cow $m(m=1-30,017) ; f(i)$ is heat stress function for herd-test-day $\mathrm{i} ; \mathrm{m}_{\mathrm{m}}$ is additive effect of regular merit of cow $\mathrm{m} ; \mathrm{h}_{\mathrm{m}}$ is additive effect of heat depression of cow $\mathrm{m} ; \mathrm{p}_{\mathrm{m}}$ is permanent environmental effect of cow $\mathrm{m}$; and $\mathrm{q}_{\mathrm{m}}$ is permanent environmental effect of heat depression of cow $i$.

The following variance structure was assumed for the bivariate analysis of NR90 and test-day milk yield.

$$
\begin{aligned}
& \operatorname{Var}\left[\begin{array}{c}
a \\
v \\
m \\
h \\
p \\
q \\
e_{N R 90} \\
e_{\text {Milk }}
\end{array}\right] \\
& =\left[\begin{array}{cccccccc}
A \sigma_{a}^{2} & A \sigma_{a v} & A \sigma_{a m} & A \sigma_{a h} & 0 & 0 & 0 & 0 \\
A \sigma_{a v} & A \sigma_{v}^{2} & A \sigma_{v m} & A \sigma_{v h} & 0 & 0 & 0 & 0 \\
A \sigma_{a m} & A \sigma_{v m} & A \sigma_{m}^{2} & A \sigma_{m h} & 0 & 0 & 0 & 0 \\
A \sigma_{a h} & A \sigma_{v h} & A \sigma_{m h} & A \sigma_{h}^{2} & 0 & 0 & 0 & 0 \\
0 & 0 & 0 & 0 & I \sigma_{p}^{2} & I \sigma_{p q} & 0 & 0 \\
0 & 0 & 0 & 0 & I \sigma_{p q} & I \sigma_{q}^{2} & 0 & 0 \\
0 & 0 & 0 & 0 & 0 & 0 & I \sigma_{e N R 90}^{2} & 0 \\
0 & 0 & 0 & 0 & 0 & 0 & 0 & I \sigma_{e M i l k}^{2}
\end{array}\right] .
\end{aligned}
$$

\section{Computations}

NR90 is a binary trait and is best analyzed by an appropriate nonlinear model, for example, the threshold model (Foulley and Gianola, 1984). Initially, variance components for NR90 were obtained from a Bayesian analysis with a threshold model by Gibbs sampling in a single long chain; for this model only, the effect of herd-year-season was considered a random environmental effect. However, mixing was very slow and exhibited cycling. Subsequently, EM REML was used for all the analysis using program REMLF90 (Misztal, 1999). The benefit of using the threshold model in this case might be small, because benefits are higher when incidences vary across levels of fixed effects (McGuirk et al., 1999).

\section{RESULTS AND DISCUSSION NR45, NR60, and NR90}

Table 3 presents the variance estimates for the linear model using REML for NR45, NR60, and NR90. Herita- bility estimates increased considerably with the increment of days waited to assign pregnancy status, from $0.06 \%$ at $45 \mathrm{~d}$ to $5.3 \%$ at $90 \mathrm{~d}$.

It should be noted that NR can be a biased indicator of fertility since low producing animals are often culled. This creates a negative correlation between production and NR and will probably inflate the heritability estimates of NR.

Regular additive variance for NR90 is almost 10 times the regular additive variance of NR45, whereas the heat tolerance additive variance for each unit eTHI for NR90 is 5 times that for NR45. These results indicate that it is worthwhile to wait until $90 \mathrm{~d}$ to record NR for genetic evaluations. These results are in contrast with results reported by Weigel and Rekaya (2000), in which estimates of the genetic variance for NR90 were not consistently higher than for NR60.

Possible explanations for the results in this study could be that NR90 offers more reliable information about true pregnancies. Estrous behavior might not have been detected at $\mathrm{d} 45$ or 60 , but at $90 \mathrm{~d}$, the average cow would have had at least 3 cycles to show estrous and be observed. At $45 \mathrm{~d}$, cows not returned to estrus are assumed to be pregnant and eventually to deliver a calf, but in reality some cows may not be showing heat or will abort. This is shown by the lower NR at 90 $\mathrm{d}$ than at $45 \mathrm{~d}$ (Table 1 ).

All further analyses were conducted for NR90 only. Figure 1 shows estimates of regular additive variance, heat tolerance variance, and total additive variance for NR90 at different levels of heat stress. When no heat stress is present, the additive variance for heat tolerance is 0 . This variance starts to increase as THI increases and is as large as the regular variance for THI $=84$. This indicates that selection for heat tolerance shown through higher NR is possible. When estimating heat tolerance variance for milk yield, Ravagnolo and Misztal (2000) found that for Georgia this variance was as important as the regular variance at THI 86 (using a threshold of 72). The earlier THI at which regular and heat tolerance variance are equal for NR90 indicates that heat tolerance for NR90 is more important relative to the regular merit than heat tolerance for milk production. The total genetic variance $(\mathrm{a}+\mathrm{fv})$ is at its lowest at THI 83 because of the relatively high estimates of the covariance between regular and heat tolerance merit (Table 3). The genetic correlation between these two terms was -0.95 , suggesting that simultaneous selection for the two traits is difficult and emphasizing the importance of selecting animals for the environment in which they are going to produce. Figure 2 shows the heritability for NR90 as THI increases. Because of the high negative additive correlation between regular merit and heat tolerance, the heri- 
Table 3. Variance component, heritability and genetic correlation estimates for NR45, NR60, and NR90 by univariate analysis. ${ }^{1}$

\begin{tabular}{lccc}
\hline & NR45 & NR60 & NR90 \\
\hline$\sigma_{\mathrm{a}}^{2}$ & 0.0013 & 0.003324 & 0.012032 \\
$\sigma_{\mathrm{v}}{ }^{2}$ & 0.00001246 & 0.000016 & 0.000061969 \\
$\sigma_{\mathrm{av}}$ & -0.00003162 & -0.0001786 & -0.00082124 \\
$\sigma_{\mathrm{e}}{ }^{2}$ & 0.2289 & 0.228 & 0.21355 \\
$\mathrm{~h}^{2}$ at $\mathrm{THI}^{2}=70$ & 0.006 & 0.014 & 0.053 \\
Corr $(\mathrm{a}, \mathrm{v})$ & -0.25 & -0.77 & -0.95 \\
\hline
\end{tabular}

${ }^{1} \mathrm{NR}=$ Nonreturn rate; number indicates days after insemination.

${ }^{2} \mathrm{THI}=$ Temperature humidity index.

tability declines until THI 83, at which point it starts to increase. It is difficult to find a biological explanation for this trend in heritability and is more than likely caused by an overestimation of the covariance between regular merit and heat tolerance. When traits have extremely low heritabilities, as is the case, correlations between the traits tend to be inflated (Luis Varona, 2001; personal communication). Thus, any improvement in the model used or in the dataset that would yield higher heritability estimates could have the consequence of obtaining lower correlations. This would enable selection for both traits.

\section{NR90 and Milk Production}

Table 4 presents the (co)variance estimates for milk yield and NR90 when correlations between the traits were ignored. Heritability for milk yield in the absence of heat stress was 0.14 . Heat tolerance variance for milk yield is as important as the regular additive variance at THI 88. Genetic correlation between regular additive merit and heat tolerance for the univariate analysis was -0.38 . All these results are very similar to those obtained in our previous study (Ravagnolo and Misztal, 2000).

Results for the bivariate model with correlations between the traits accounted for are shown in Table 5. Genetic correlation between regular merit for milk yield and for NR90 was -0.41 , indicating that the relationship between milk yield and NR90 is moderately antagonistic and that simultaneous selection for both traits is possible. This agrees with several studies that have found a mild but antagonistic relationship between fertility and milk yield (Abdallah and McDaniel, 2000; Campos et al., 1994), whereas some other studies have found correlations around 0 (Raheja et al., 1989). Other studies have found a slight but positive relationship between conception rate and NR with milk production (Weller, 1989; Roth et al., 1999).

Genetic correlation between heat tolerance for milk yield and heat tolerance for NR90 was -0.04, indicating that the metabolic and physiological processes that are

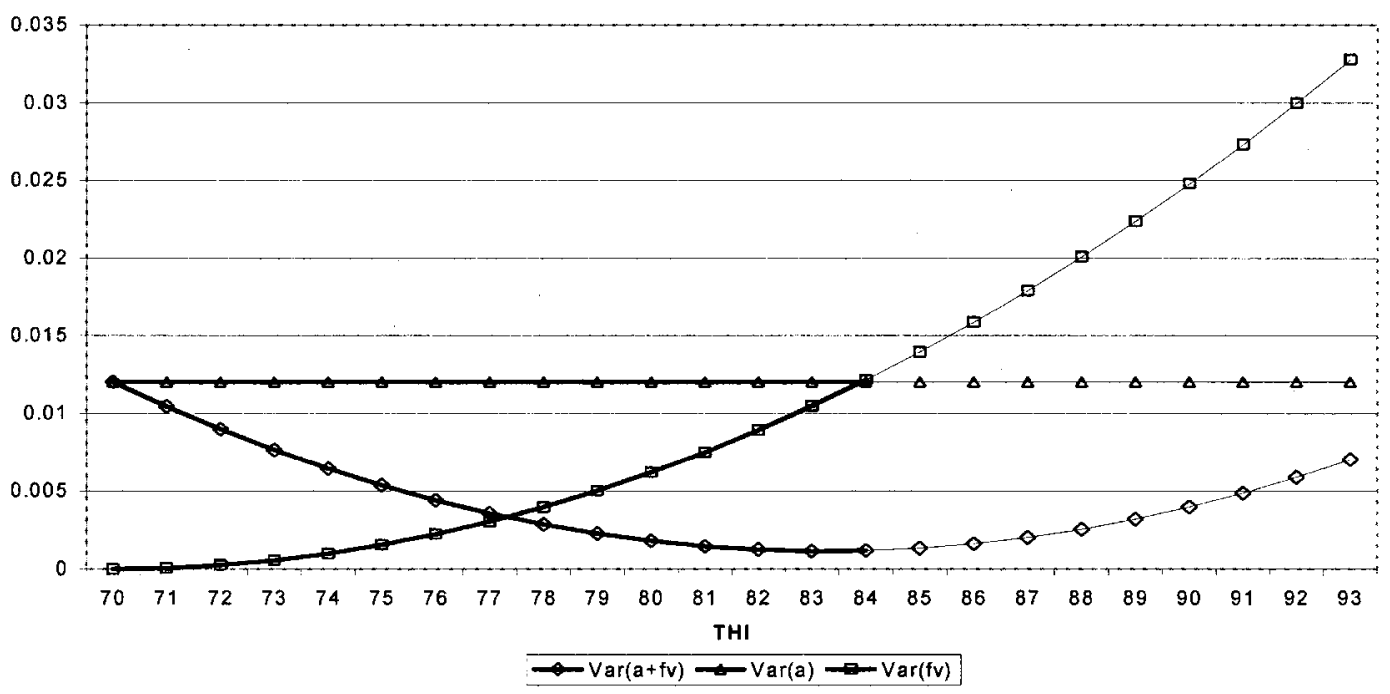

Figure 1. Variance estimates for nonreturn rate $90 \mathrm{~d}$ after insemination in first lactation by univariate analysis. THI $=$ Temperaturehumidity index. 
Table 4. Variance component and heritability estimates for milk and $\mathrm{NR} 90^{1}$ by bivariate analysis with covariances among the traits set to 0 .

\begin{tabular}{lcll}
\hline & Milk & NR90 & \\
\hline$\sigma_{\mathrm{m}}{ }^{2}$ & & $\sigma_{\mathrm{a}}{ }^{2}$ & 0.01203 \\
$\sigma_{\mathrm{h}}{ }^{2}$ & 4.8707 & $\sigma_{\mathrm{v}}{ }^{2}$ & 0.00006197 \\
$\sigma_{\mathrm{mh}}$ & 0.0155 & $\sigma_{\mathrm{av}}$ & -0.0008212 \\
$\sigma_{\mathrm{p}}{ }^{2}$ & -0.1056 & $\cdots$ & $\cdots$ \\
$\sigma_{\mathrm{q}}$ & 16.4120 & $\cdots$ & $\cdots$ \\
$\sigma_{\mathrm{pq}}$ & 0.04143 & $\cdots$ & $\cdots$ \\
$\sigma_{\mathrm{e}}^{2}$ & -0.4089 & $\sigma_{\mathrm{e}}{ }^{2}$ & 0.2135 \\
$\mathrm{~h}^{2}$ at $\mathrm{THI}^{2}=70$ & 13.0570 & & 0.053 \\
\hline
\end{tabular}

${ }^{1} \mathrm{NR} 90=$ Nonreturn rate at $90 \mathrm{~d}$ after insemination.

${ }^{2} \mathrm{THI}=$ Temperature humidity index.

responsible for heat tolerance for milk and for reproduction are different.

The correlation between regular merit and heat tolerance for NR90 was -0.43 , substantially lower than -0.95 , which was obtained in the univariate model. It seems that the additional information provided by milk yield had an important effect on covariance estimates. Single-trait evaluations can be biased when animals are being selected for a correlated trait.Using a multivariate analysis with the complete information by which the selection was performed obtains unbiased evaluations (Pollak et al., 1984). The change in estimates using univariate and multivariate analysis could be because the multitrait-analysis accounts for selection, and animals are strongly selected for milk yield.
In this case, a univariate analysis of NR90 is going to be biased.

Figure 3 shows regular, heat tolerance, and total additive variance for NR90 from the bivariate analysis. Because covariance between regular and heat tolerance is much smaller, although still negative, than in the univariate case, additive variances are higher as THI increases. This is reflected in an average higher heritability for NR90 but not for milk (Figure 4).

Genetic correlation between regular merits for milk yield and heat tolerance for NR90 was 0.02 , and between regular merit for NR90 and heat tolerance for milk yield was 0.14 . The small difference between these correlations might be due to the different amount of information available for the estimates of each correlation.

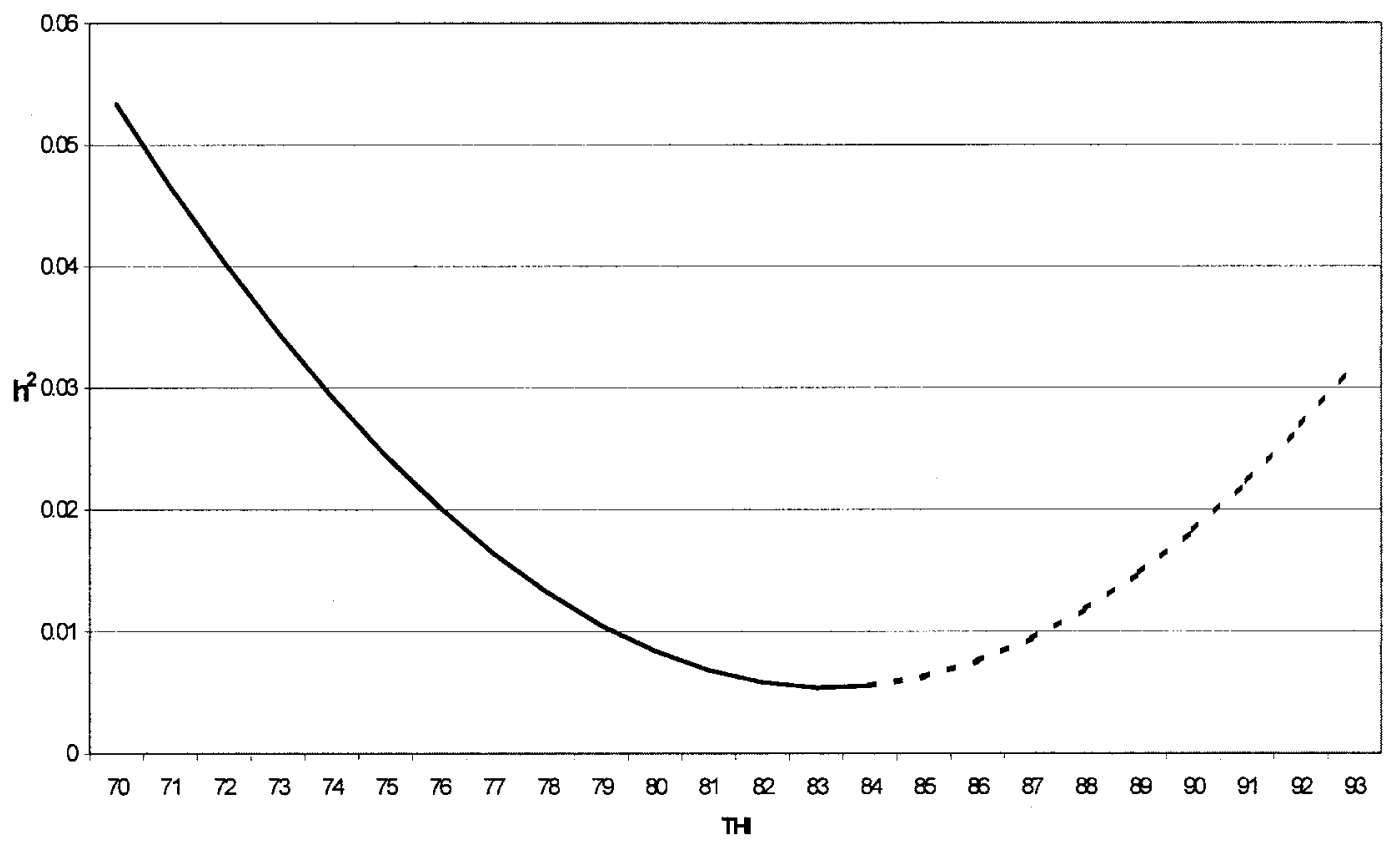

Figure 2. Heritability estimates for nonreturn rate $90 \mathrm{~d}$ after insemination in first lactation by univariate analysis. THI $=$ Temperaturehumidity index. 


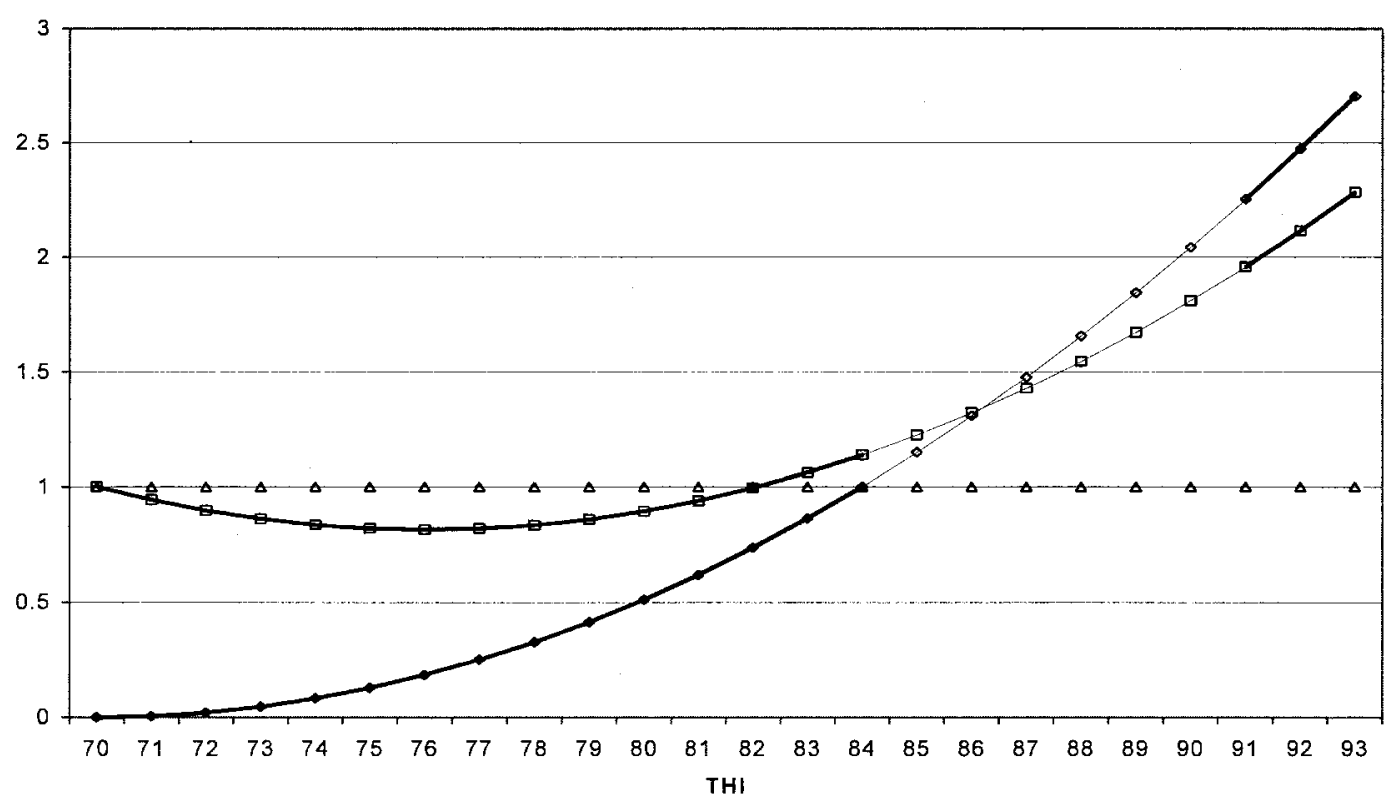

$\Delta \operatorname{Var}(\mathrm{a}) \rightarrow \operatorname{Var}(\mathrm{v}) \rightarrow \operatorname{Var}(\mathrm{a}+\mathrm{v})$

Figure 3. Variance estimates for nonreturn rate $90 \mathrm{~d}$ after insemination by bivariate analysis. THI $=$ Temperature-humidity index

\section{Limitations}

In this study, records were from herds with different management practices, and weather records were obtained from weather stations. West et al. (2000) looked at relationship between production and THI in one herd with consistent management using on-the-farm THI measurements. Their estimates of heat depression for milk were about two times higher than those obtained by Ravagnolo et al. (2000). Therefore, the estimates of heat depression in this study may be underestimated in the order of two times, and the variances caused by heat stress may be underestimated in the order of four times.

\section{Further Analyses}

Other analyses have been carried out as part of the same project. A univariate model with quadratic ran- dom regression was run to account for potential nonlinearity of NR with regard to THI. A bivariate model was run with first and second parity NR as separate traits to examine whether these traits can be treated as the same trait. The results from these analyses are not shown because after running the bivariate analyses with milk, it became obvious that analyses of NR without milk as a correlated trait likely results in biased estimates. The amount of data and resources were insufficient to run the new models with an extra trait of milk.

\section{CONCLUSIONS}

The heritability for NR90 was much higher than for NR45 and NR60. Therefore, NR90 is the preferred trait among other NR traits for genetic selection. The vari-

Table 5. (Co)variance and correlation estimates for milk and NR90 by bivariate analysis. ${ }^{1}$

\begin{tabular}{lccccc}
\hline & \multicolumn{2}{c}{${\text { NR90* } 10^{2}}$} & & \multicolumn{2}{c}{ Milk } \\
\cline { 2 - 3 } \cline { 5 - 6 } & Gen. (a) & H. Tolerance (v) & & Gen. (m) & H. Tolerance (h) \\
\hline Regular (a) & 1.002 & -0.0309 & & -0.9403 & 0.01385 \\
H. tolerance (v) & -0.43 & 0.00511 & & 0.003482 & -0.0002619 \\
Regular (m) & -0.41 & 0.02 & & 5.1370 & -0.1027 \\
H. tolerance (h) & 0.14 & -0.04 & -0.45 & 0.01018 \\
$\sigma_{\mathrm{e}}{ }^{2}$ & & 21.24 & & & 13.05 \\
\hline
\end{tabular}

${ }^{1}(\mathrm{Co})$ variances on diagonal and over diagonal; correlations under diagonal.

${ }^{2}$ Nonreturn rate $90 \mathrm{~d}$ after insemination. 


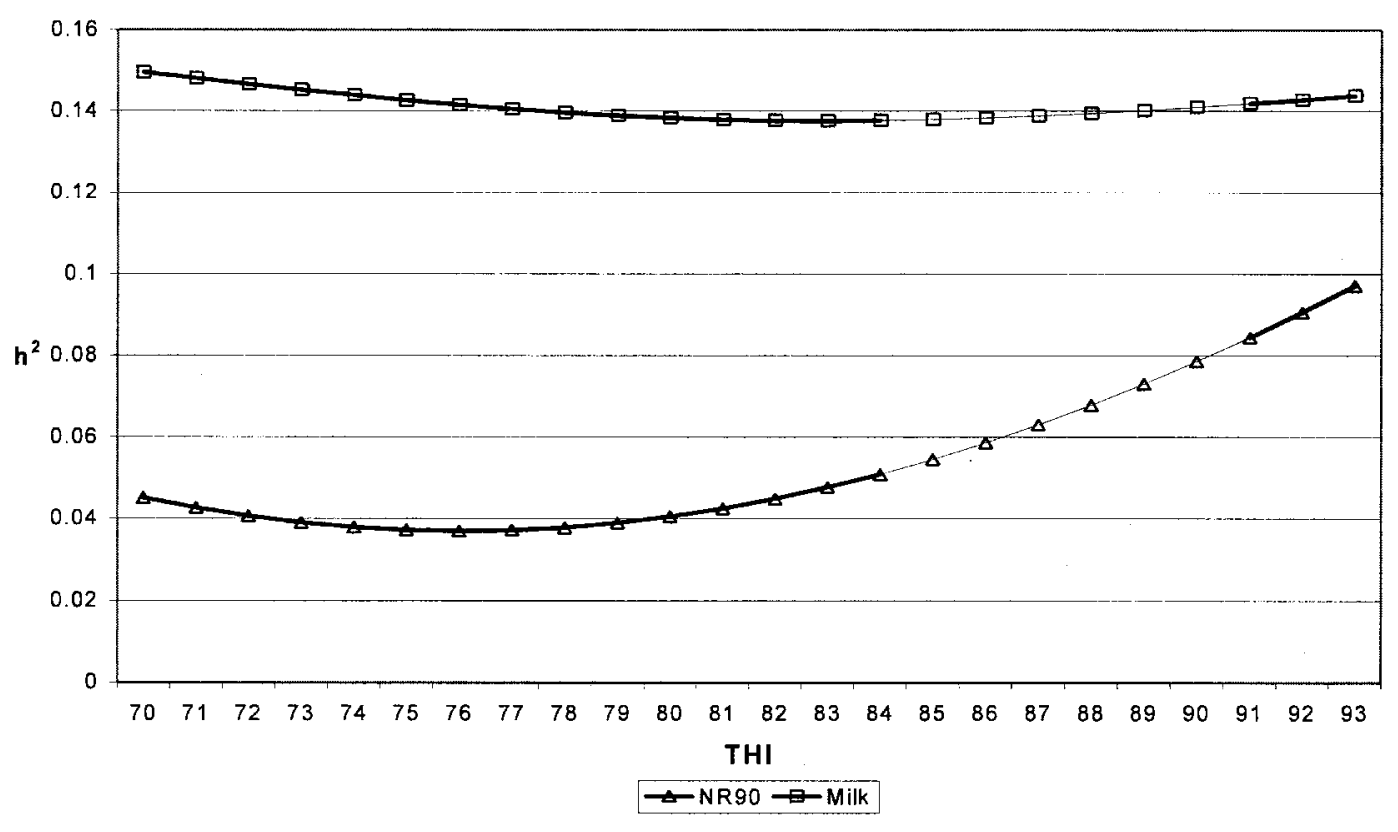

Figure 4. Heritability estimates for nonreturn rate $90 \mathrm{~d}$ after insemination and milk production by bivariate analysis. THI $=$ Temperaturehumidity index.

ance of heat stress is zero at THI 70 but is as large as a general additive variance at $\mathrm{THI}=84$ for NR90.

Relationship between milk yield and NR90 is moderate, and simultaneous selection for both traits is possible. The genetic relationship between heat tolerance for milk yield and heat tolerance for NR90 is low. Important differences in estimates for NR90 between univariate and bivariate analyses indicates that univariate estimates are biased, caused by strong selection for milk yield, which was not accounted for in the univariate case.

\section{ACKNOWLEDGMENTS}

Appreciation is expressed to Gerrit Hoogenboom (UGA) for providing weather data and assistance during this study, George Wiggans (USDA) for providing production data and for John Clay, Dairy Records Managements Systems, Pennsylvania DHIA and AgSource for providing reproductive data. This study was partly supported by the Holstein Association of America.

\section{REFERENCES}

Abdallah, J. M., and B. T. McDaniel. 2000. Genetic parameters and trends of milk, fat, days open, and body weight after calving in North Carolina experimental herds. J. Dairy Sci. 83:1364-1370.

Bianca, W. 1965. Reviews of the progress of dairy science. Dairy Res. 32:291-345.

Branton, C., J. E. Johnston, and G. D. Miller. 1953. Physiological and hereditary responses of lactation Holstein-Freisian and Jersey cows to natural environmental temperature and humidity. J. Dairy Sci. 36:585.
Buffington, D. E., A. Collazo-Aruchu, H. H. Canton, D. Pritt, W. Thatcher, and R. J. Collier. 1981. Black globe-humidity index (BGHI) as comfort equations for cows. Trans. Am. Soc. Agric. Eng. 7:329.

Campos, M. S., C. J. Wilcox, C. M. Becerril, and A. Diz. 1994. Genetic parameters for yield and reproductive traits of Holstein and Jersey cattle in Florida. J. Dairy Sci. 77:867-873.

Ewer, T. L. 1974. What do we mean by stress? Vet. Rec. 95:180-182.

Foulley, J. L. and D. Gianola, 1984. Estimation of genetic merit bivariate "all or none" responses. Genet. Sel. Evol. 16:285-306.

Gomes da Silva, R. 1973. Improving tropical beef cattle by simultaneous selection for weight and heat tolerance. Heritabilities and correlations of the trait. J. Anim. Sci. 37:637-642.

Hansen, P. J., M. Drost, R. M. Rivera, F. F. Paula-Lopes, Y. M. AlKatanani, C. E. Krininger III, and C. C. Chase. 2000. Adverse impact of heat stress on embryo production: causes and strategies for mitigation. Theriogenology 55:91-103.

McDowell, R. E., J. C. Wilk, and C. W. Talbott. 1996. Economic viability of crosses of Bos Taurus and Bos Indicus for dairying in warm climates. J. Dairy Sci. 79:1292-1303.

McGuirk, B. J., I. Going, and A. R. Gilmour. 1999. The genetic evaluation for UK Holstein Friesian sires for calving ease and related traits. Anim. Sci. 68:413-422.

Misztal, I. 1999. REMLF90 Manual.ftp://num.ads.uga.edu/pub/ blupf90/docs/blupf90.pdf. Accessed March 29, 2000.

Nardone, A., and A. Valentini. 2000. The genetic improvement of dairy cows in warm climates. Proceedings of the joint ANPAEAAP-CIHEAM-FAO symposium on Livestock production and climatic uncertainty in the Mediterranean. Agadir, Morocco. EAAP Publication No. 94, 2000.

NOAA. 1976. Livestock hot weather stress. U. S. Department of Commerce, National Oceanic and Atmospheric Administration, National Weather Service Central Region. Regional Operations Manual Letter C-31-76.

Olson, T. A., A. C. Hammond, and C. C. Chase, Jr. 1997. Evidence for the existence of a major gene influencing hair length and heat tolerance in Senepol cattle. J. Anim. Sci. 75(Suppl. 1):147. (Abstr.)

Pollak, E. J., J. van der Werf, and R. L. Quaas. 1984. Selection bias and multiple trait evaluation. J. Dairy Sci. 67:1590-1595. 
Ravagnolo, O., and I. Misztal. 2000. Genetic component of heat stress in dairy cattle, parameter estimation. J. Dairy Sci. 83:2126-2130.

Ravagnolo, O., I. Misztal, and G. Hoogenboom. 2000. Genetic component of heat stress in dairy cattle-development of heat-index function. J. Dairy Sci. 83:2120-2125.

Ravagnolo, O., and I. Misztal, 2002. Effect of heat stress on nonreturn rate in Holsteins: Fixed-Model Analyses. J. Dairy Sci. 85:31013106.

Raheja, K. L., E. B. Burnside, and L. R. Schaeffer. 1989. Relationships between fertility and production in Holstein dairy cattle in different lactations. J. Dairy Sci. 72:2670-2678.

Roth, A., E. Strandberg, B. Berglund, U. Emanuelson, and J. Philipsson. 1999. Genetic correlations among female fertility traits and milk production in different parities in Swedish dairy cattle.
In: Metabolic stress in dairy cows. Occasional Publication No. 24-British Society of Animal Science.

Seath, D. M. 1947. Heritability of heat tolerance in dairy cattle. J. Dairy Sci. 30:137-144.

Thaller, G. 1997. Genetics and breeding for fertility. Interbull Mtg. Grub. Uppsala, Interbull Bull. No. 18.

Weigel, K. A., and R. Rekaya. 2000. Genetic parameters for reproductive traits of Holstein cattle in California and Minnesota. J. Dairy Sci. 83:1072-1080.

Weller, J. I. 1989. Genetic Analysis of Fertility Traits in Israeli Dairy Cattle. J. Dairy Sci. 72:2644-2650.

West, J. W., B. G. Mullinix, and J. K. Bernard. 2000. Influence of environmental conditions on body temperature, dry matter intake, and milk yield for lactating cows from spring through summer in the Southeast. J. Dairy Sci. 83(Suppl. 1):232. (Abstr.) 